\title{
Spontaneous pattern discrimination in the rat: A further analysis
}

ROBERT M. BERRY,I RICHARD L. ROGERS, AND JAMES E. MCCARROLL, DEPARTMENT OF PSYCHOLOGY, UNIVERSITY OF ARKANSAS, Fayetteville, Ark. 72701

One of two visual stimulus patterns was presented to 24 male albino rats for a 10-min session. Following a 2 min intersession interval, Ss received an additional 10-min exposure either to the same or a different pattern. The activity scores were recorded for both sessions. The major findings were: (a) a significant pattern preference, (b) no significant "novelty" effect, and $(c)$ a significant decrease in activity over sessions.

A standard reference experiment for the influence of novelty on exploratory behavior is a study by Thompson \& Solomon (1954). These investigators confined white rats in a living box for a $24 \mathrm{~h}$ period and then presented these Ss with a striated pattern in an adjacent stimulus box. The time spent exploring the pattern was recorded. Follwoing a 2 min intersession interval (ISI), one half of the Ss were again exposed to the striated pattern while one half were exposed to a novel triangular pattern. Exploration time was again recorded. During the second session there was significantly more exploratory behavior exhibited by the group exposed to the triangle. Thompson and Solomon concluded that the Ss had discriminated between the two patterns and that the novelty of the triangle was the motivating factor. However, the greater exploration by the group exposed to the triangle cannot be unequivocally attributed to the novelty of the triangle. It would be just as reasonable to conclude that the rats preferred one visual pattern over the other since the failure to include a control group exposed to the patterns in a reverse order resulted in the confounding of pattern "novelty" and pattern preference.

The present study was designed to investigate the exploration of visual pattern under conditions which allowed the effects of pattern novelty and pattern preference to be independently evaluated.

Method

The Ss were 24 male albino rats, 90-110 days old. They were divided into four groups with each group consisting of six rats.

The apparatus consisted of three plywood living boxes, $8 \frac{1}{2} \times 8^{1 / 2}$ $x 10$ in. painted flat black, with wire mesh tops and floors and vertically sliding wooden doors. The two stimulus patterns were (a) an inverted isosceles triangle, base 6 in., height $5 \frac{1}{2}$ in. and (b) six vertical striations, width $1 / 2$ in., height $5 \frac{1}{2}$ in., and $1 / 2$ in. apart. The total amount of white in both patterns was equal. The patterns could be inserted and removed as panels in the rear inside wall of a flat black stimulus box $8 \frac{1}{2} \times 8 \frac{1}{2} \times 6$ in. The floor of the stimulus box was constructed of plywood and was covered with a waxpaper panel which was replaced after each session of the experiment.

Only one side of the stimulus box was open, that directly opposite the pattern. Thus, by fitting the open end to the front of a living box, and then quietly removing the door of the latter, the pattern could be exposed to the Ss.

Procedure

Each rat was placed in one of the living boxes, where food and water were available for a $24 \mathrm{~h}$ adaptation period. Following this, each animal was tested for two 10-min sessions as follows:

Session A. The striated stimulus pattern was presented in the manner described to Ss of Groups 1 and 2 . After $10 \mathrm{~min}$ the door of the living box was closed and the stimulus box removed for 2 min. During this period the panel was replaced.

The same procedure was followed for Groups 3 and 4 except that the triangular stimulus pattern was presented.

Session B. The striations were again shown to Ss in Group 1 (Striation-Striation group) as well as to Ss in Group 4 (TriangleStriation group). The triangular pattern was exposed to $\mathrm{Ss}$ in Group 2 (Striation-Triangle) and in Group 3 (Triangle-Triangle).

Three measures of exploratory activity were used: (M1) Time spent sniffing at a stimulus pattern, (M2) Time spent with all four feet in the stimulus box, and (M3) Time spent looking at a stimulus pattern, i.e., the time during which a rat had its nose pointed toward a pattern, and its forepaws resting on the wooden ledge separating the living box from the stimulus bo.

The Es recording $M 2$ and $M 3$ were positioned behind the stimulus box and were always "blind" to the pattern in the stimulus box. The $E$ recording $M 1$ always changed the patterns and was the only $E$ aware of which pattern was being presented. Each measure was recorded by stop watch in seconds for every 10 -min session.

Results and Discussion

Pattern preference was tested by comparing the combined activity scores of Groups 1 and 2 with the combined activity scores of Groups 3 and 4 for Session A. Separate t tests were conducted for each measure. No differneces were found between the two groups on $\mathrm{M} 3(\mathrm{t}=.93$, df $=22, \mathrm{p}>.05)$ or $\mathrm{M} 2(\mathrm{t}=1.99$, $\mathrm{df}=22, .05<\mathrm{p}<.10$ ) but a significant difference was obtained on M1 $(t=2.87, \mathrm{df}=22, \mathrm{p}<.01)$. These results indicate a preference for the striated stimulus pattern.

The effect of novelty was tested by combining the scores of the groups receiving a different pattern on the second $10-\mathrm{min}$ session (Session B) and comparing these scores with the combined scores of the groups receiving the same pattern during Session B. None of these differences approached the required level of significance.

There was some indication of a general decrease in the activity scores in Session B from that of Session A and additional tests were conducted to determine if this difference was reliable. All of the scores on Session A were combined and compared with the combined scores on Session B for all three measures. A significant effect was obtained between sessions on $\mathrm{M} 1(\mathrm{t}=3.37$, $\mathrm{df}=23, \mathrm{p}<$ $.01)$ but not on M2 $(\mathrm{t}=2.05, \mathrm{df}=23, .05<\mathrm{p}<.10)$ or M3 $(\mathrm{t}=$ $.42, \mathrm{df}=23, \mathrm{p}>.05$ ).

The present failure to find a significant relationship between novelty and exploratory behavior contradicts the previous findings of Thompson \& Solomon (1954). The present demonstration of a pattern preference suggests the possibility that the findings of Thompson \& Solomon (1954) may be attributed to pattern preference and not to novelty. This suggestion recognizes that a reversal in pattern preference would have to be assumed for the Ss in the two experiments. Such individual differences in visual pattern preference have been previously noted by Law (1954).

Independent of the issue of whether novelty constituted the exploratory motive in the Thompson \& Solomon (1954) study is the question of whether their Ss exhibited pattern discrimination at all. Since their stimulus patterns were permanently fixed in different stimulus boxes, the presentation of the same visual pattern in the second session also reintroduced other potentially familiar cues, e.g., odor trails, which could serve to attenuate an exploratory response. By contrast, the introduction of a novel visual pattern during the second session introduced an entirely novel stimulus complex and thus potential exploratory cues in addition to the visual pattern. This suggests that the $S s$ in the Thompson \& Solomon (1954) experiment could have been discriminating between "novel" and familiar cues and not between patterns. According to this analysis, an exploratory decrement would be expected during the second session if, as in the present study, the only part of the stimulus complex which underwent change was the visual pattern. The present finding of a significant effect between sessions supports such an interpretation.

Until further studies are conducted which include a counterbalanced order of stimulus presentation and control of extraneous cues, the question of spontaneous pattern discrimination in the rat remains open.

\section{REFERENCES}

LAW, O. T. Preference in the rat for vertical or horizontal stripes after training on a white-black discrimination. Amer. J. Psychol, 1954, 67, 714-716.

THOMPSON, W. R., \& SOLOMON, L. M. Spontaneous pattern discrimination in the rat. J. comp. physiol, Psychol., 1954, 47, 104-107. NOTE

1. Now at Valparaiso University, Valparaiso, Ind. 46383. 